Published as: Oliver, J.J. (2016). High velocity markets drive adaptive capabilities, Strategic Direction, Vol. 32, Iss 1, pp. 5 - 7.

\title{
High velocity markets drive adaptive capabilities
}

At the core of every good strategy is the word 'advantage'. Over the years management consultants and scholars have described this advantage as being competitive, differential, comparative, scale and sustainable to name but a few perspectives. However, with many markets now exhibiting high velocity conditions (Oliver, 2012) firms are adapting their corporate level strategy, business models, resources and capabilities at an increasingly frequent rate. This paper argues that at the core of every strategy, there now needs to be the word 'adaptability'.

One of the most topical management issues today is how firms sustain their business in markets that are increasingly characterized by volatility, numerous disruptions and uncertainty. The idea that corporate strategy needs to emphasize the adaptation of a firm faster than rivals means that adaptive capability should be considered as a competitive advantage in itself. Therefore, in high velocity market conditions the ability to adapt a firm will be the most effective way to sustain a business the in the long-term.

How do firms sustain themselves through adaptation?

Adaptive capability should not be confused with the Darwinian view of natural selection where the competitive survival of the firm is determined by trial, error and how successful they are at incrementally adapting the business to the prevailing environmental conditions. The strategic adaptation of a firm is not achieved by 'chance' but by rationale strategic planning and the desire to achieve an organizational goal that is dictated by changes in the competitive environment.

The concept of Adaptive Advantage is not new. However, it has received surprisingly little attention by way of theoretical development and empirical testing. To date, there has been much discussion on the need for organizational adaptation, rather than the advantage it can deliver to a firm who embraces the principle. Reeves and Deimler (2011) argued that firms could develop new adaptive learning capabilities that would reshape their business, through a process of managed evolution, which would deliver superior firm performance. These capabilities were considered to be the:

- ability to detect and act on signals in the external environment;

- ability to experiment and develop expedient low cost ideas;

- $\quad$ ability to manage complex and dynamic multi-stakeholder eco-systems;

- ability to mobilize resources by empowering people to proactively respond to changes in the environment.

Adaptive Advantage in Action

Recent research by Bournemouth University (UK) has examined the ability of UK media firms to gain an 'adaptive advantage' in the market place. The research investigated three areas of business activity.

1. An assessment of the competitive environment and outlook for the industry

The outlook for the UK Media Industry was extremely favourable with $89 \%$ of executives agreeing that the year ahead would be positive. This optimism is likely to be the result of improved macroeconomic conditions that have fed down to industry level, since the majority of executives (63\%) said that their ability to develop strategy was 'not' being hampered by uncertain market conditions. They also commented that their corporate advertising revenues were likely to increase (68\%). However, there was some doubt with regard to some aspects of their competitive environment. For example, $82 \%$ stated that the industry was experiencing a high rate of turbulence and change and that only 54\% of executives agreed that their business planning assumed economic growth in the year ahead. The 
Published as: Oliver, J.J. (2016). High velocity markets drive adaptive capabilities, Strategic Direction, Vol. 32, Iss 1, pp. 5 - 7.

majority (62\%) of executives also commented that it was difficult to protect their core business whilst building new revenue streams.

\section{An assessment of media firm capabilities}

Corporate capabilities are derived from the an organization's ability to manage and develop their resources in a way that differentiates them from the competition. These capabilities provide customers with value and a competitive advantage for the firm in the market place. Capabilities are the minimum threshold of resources that are required to satisfy market requirements, but in high velocity markets, these resources need to be regularly renewed and refreshed in order to meet the dynamics of new market conditions and sustain the corporate objectives of the firm.

The survey data provided some interesting observations on how media organizations were adapting their resource base to changing market conditions. In response to the question 'Our core business is running out of steam and needs new capabilities' the majority (68\%) of executives felt that their core business was robust, which suggests that media firm sustainability is being achieved through the adaptation of their resources and capabilities in line with fast changing market conditions. In terms of how these capabilities translate into financial returns for the firm, $64 \%$ of executives believed that their firm's current capabilities were sufficient to achieve their financial objectives in the year ahead.

The survey asked executives to comment on their firm's corporate strategy and 92\% stated that their strategy was aspirational. When asked whether their corporate strategy would include strategic alliances and other forms of collaborative activity to access new capabilities and boost innovation, $88 \%$ of executives strongly agreed or agreed with this statement. Indeed, innovation was central to most executive responses, with $64 \%$ of them saying that their company would focus more on innovation than cost reduction in order to remain competitive.

Refreshing a firm's resource base in order to create new capabilities, requires significant and long-term strategic investments in Research \& Development, infrastructure, people and organizational processes. The survey data indicated that many media firms (56\%) would make significant investments in Research \& Development in the year ahead and a further 52\% would make investments in infrastructure, people and processes.

\section{An assessment of media firm ability to adapt to new industry dynamics}

A changing and dynamic industry encourages firms to experiment in order to sustain their business and remain competitive. This experimentation is often seen in adaptive processes relating to strategy making, business models and wider issues of organizational change.

The survey data indicated that the majority of media firms (74\%) placed an emphasis on experimentation in order to keep pace with structural market changes. However, the process of making strategy showed that just over half (52\%) of executives developed emergent and experimental strategies, whilst the remaining executives (48\%) confirmed that their strategies were derived from the more traditional 'analysis and design' approach. Executive views diverged more substantially when considering business model adaptation and broader views on organizational change since most firms were adapting their business models (70\%) in line with changes in the industry and yet when asked if their firms were adapting too slowly to change, around half (57\%) agreed. 
Published as: Oliver, J.J. (2016). High velocity markets drive adaptive capabilities, Strategic Direction, Vol. 32, Iss 1, pp. 5 - 7.

\section{Conclusion}

Perhaps the most compelling finding to support the idea that organizations need to place adaptive advantage at the centre of their corporate strategy is that research by Bournemouth University in 2012 found that 33\% of media firms believed that they were adapting too slowly to change, and by 2015, this figure had risen to 57\%. This finding is interesting and supports the idea that firms can gain an 'adaptive advantage' over their competition by adapting their business at a faster rate than their rivals.

\section{References}

Oliver, J.J. (2015). Media Outlook: A Survey of UK Media Trends and Firm Capabilities. Bournemouth University.

Oliver, J.J. (2012). Winning in high velocity markets: the case of BSkyB, Strategic Direction, Volume 28, Issue 10 , pp. $3-5$.

Reeves, M. and Deimler, M., (2011). Adaptability: The New Competitive Advantage. Harvard Business Review. Vol. 89 Issue 7/8, pp.134-141. 